\title{
WORLD VIEW: \\ THE 1998 STRATEGIC ASSESSMENT \\ FROM THE STRATEGIC STUDIES INSTITUTE
}

\author{
Edited by
}

Earl H. Tilford, Jr.

February 26, 1998 